\title{
El personaje en Esopo y Augusto Monterroso
}

Emmanuel Jaén*

Palabras clave: $<$ Fábula $><$ Esopo $><$ AugustoMonterroso $><$ análisis literario>

El presente escrito es una aproximación al análisis de los personajes en las fábulas de Esopo y de Augusto Monterroso. La historia de la literatura nos enseña que el primer autor sirve de referencia e influencia al segundo. En el caso de Monterroso sus fábulas muestran variaciones y alejamientos de la tradición Esópica. Por tanto, se trata de establecer aquí y en un breve número de fábulas de ambos autores, las características pertinentes de los personajes y se constata asimismo, la existencia de similitudes o diferencias y por supuesto, la función que de ello se deriva. Se seleccionó para este propósito las siguientes obras: Fábulas esópicas, de Esopo; y La oveja negra y demás fábulas; de Augusto Monterroso.

\section{Introducción}

La fábula es un género o composición breve constituida casi siempre por un sólo episodio. Puede componerse en prosa o en verso y sus protagonistas son animales y seres inanimados y como se sabe, su contenido persigue un propósito moralizante e ideológico. Tradicionalmente la fábula literaria termina en breves versos o en palabras de carácter gnómico y ello constituye la moraleja (ALBA: 36-44).

Mesopotamia fue la cuna histórica de la fábula y posteriormente el género se bifurcó y extendió hacia la India y Grecia. En occidente el máximo representante reconocido fue Esopo de quien apenas se conocen inciertos datos biográficos. Si Esopo existió, vivió entre el

* Emmanuel Jaén. Lic. en Literatura por la Universidad Pedagógica Nacional Francisco Morazán UPNFM y catedrático del Depto. de Arte de la UPNFM. 
620 y el 560 a. C. Después de este autor la fábula se cultivó en Roma por Fedro quien prácticamente la introdujo entre los latinos a partir de la tradición griega. Este autor fue muy estimado y reconocido a lo largo del medioevo pero su existencia es desconocida en la modernidad. En España particularmente y de donde procede nuestra tradición fabularia, el género se extendió gracias a la civilización árabe que ocupó durante más de ochocientos años el sur de la península ibérica. España retomó el género pero también lo enriqueció gracias a las tradiciones y vertientes orientales, así como a las de procedencia griega y latina (Marchesse y Forradelas: 161).

En el Siglo de Oro diversos autores peninsulares incorporaron apólogos a sus libros por ejemplo, los encontramos en la novela picaresca española en obras como Vida del Pícaro Guzmán de Alfarache. Mateo Alemán el autor de esta obra, concluye cada aventura del héroe con una valoración similar a la moraleja que acompaña siempre a toda fábula. Otros autores del siglo XVI que introdujeron elementos fabularios fueron Lope de Vega en su poema La Gatomaquia. Sin embargo, es hasta el siglo XVIII a través de los mejores cultivadores del género como Félix María de Samaniego (1745-1801) y Tomás de Iriarte (1750-1791) que se compondrán en España y con cierta regularidad libros exclusivamente de fábulas. Hasta entonces en la literatura ibérica los apólogos se incorporaban tímidamente en verso o en prosa para reforzar un argumento o situación en géneros que abordaban temas de carácter didáctico-moral (Ibid.: 40-43).

La incorporación de fábulas en la literatura española resultó abundante y procedió en buena medida de esa rica corriente medieval, de tal forma que esta tradición llegó y se introdujo sin ningún percance en la literatura latinoamericana. En Centroamérica Augusto Monterroso (1921-2002), es considerado por la crítica internacional como un innovador y diestro relator de fábulas. Las características de su obra se resumen brevemente por el laconismo, la síntesis y el humor y todo ello gracias a un lenguaje preciso y sencillo (Barraza: 104).

\section{Fábula y personaje}

El análisis de los personajes en ambos autores se realiza a partir de 
la Teoría de la narrativa de Mieke Bal, quien señala que en una narración los actores no son necesariamente humanos. Considera asimismo, que el material que constituye la fábula se divide en elementos "fijos" y "mutables", es decir, en objetos y procesos. Los "objetos" comprenden no sólo actores los cuales son más o menos estables, sino que bien pueden ser lugares y cosas. Bal precisa, de igual modo, que el objeto no siempre es una persona y que ésta, aspira a alcanzar cierto estado. Otros objetos de intención identificados en las fábulas son riquezas, posesiones, sabiduría, amor, felicidad, un lugar en el cielo, un lecho donde morir, un aumento de sueldo una sociedad justa, etc. Con ello, el actante, y el actor -es decir, su representación concreta-, se encuentran en teoría desconectados de la encarnación en una persona. Empero el principio de la fábula reside en su aspecto de intención, el resultado práctico es (en las fábulas con animales), que el sujeto normalmente es un animal personificado (Bal: 13-133).

\section{Caracterización de personajes en las Fábulas de Esópo:}

Bal en su estudio sobre los personajes señala que las entidades referenciales a causa de su evidente correspondencia con un marco de referencia, actúan según el modelo que conocemos por otras fuentes (Ibid: 29). En el caso de los personajes contenidos en las fábulas de Esopo es necesario determinar en primera instancia, esa conducta -predecible o referencial-, para establecer el desenvolvimiento de éstos. Por ello es posible determinar, en un estudio comparativo y a partir del establecimiento del comportamiento de los personajes de las fábulas esópicas, los giros o cambios existente entre los personajes de Esopo y de Augusto Monterroso. Para tal propósito se seguirá en este trabajo el esquema propuesto por Bal sobre los ejes semánticos pertinentes a través de los cuales se encuentran y se pueden establecer similitudes y oposiciones (o diferencias) entre los personajes (Ibid: 94).

En sus Fábulas Esopo ubica rápidamente a los personajes en un espacio compuesto por la naturaleza (bosque, valle, río, caminos, etc). Evidentemente la función analógica que cumple el entorno de los animales, es semejarse a la sociedad de los hombres. En ella se desenvuelven los personajes con el propósito de mostrar los vicios o 
virtudes humanas. A continuación y de manera sucinta se muestra una caracterización de las conductas y acciones que presentan los animales en las fabulas de Esopo. Para ello se sigue el siguiente procedimiento: se nombra el animal, se establece su comportamiento o acciones mostradas y se cita la fábula de donde procede la información:

El conejo (la liebre): Dispuesto a morir frente a la vida azarosa que le dan los perros ("Las liebres y las ranas").

El gallo: Ignorante, libidinoso ("El gallo y la margarita",12); listo y prudente ("La zorra, el gallo y los perros").

Lobo: Insolente, malévolo, perverso, emplea la fuerza para imponerse frente a los débiles, de nada sirve la verdad y la razón frente a sus argumentos ("El lobo y el cordero", 11); desagradecido no recuerda ni devuelve favores recibidos ("El lobo y la grulla", 13); mentiroso ("El cordero y el lobo") y ("La cabra, el cabrito y el lobo"); testifica falsamente para dañar a otros ("El ciervo, la oveja y el lobo"); sabio y reflexivo ("El lobo y el busto"); falso ("El lobo, la zorra y el mono"); egoísta y desconfiado ("La zorra y el lobo"); aprecia la libertad sobre los bienes ("El perro y el lobo"); establece acuerdos ventajosos para él (“Los lobos y las ovejas").

El perro: Falso, injusto aliado del lobo, el buitre y el milano para dañar a la oveja ("El perro y la oveja", 14); codicioso ("El perro y el pedazo de carne", 15); leal ("El ladrón y el perro"); despreciado en su vejez por el amo, reflexivo ("El cazador y el perro"); conformista ("El perro y el lobo").

Cordero (oveja): Humilde, víctima del lobo que lo devora sin ningún motivo ("El lobo y el cordero", 11); víctima del perro que le roba sus bienes e inculpa injustamente ("El perro y la oveja",14); incrédulo y desconfiado frente al lobo ("El cordero y el lobo"); objeto de robo pero lista ("El ciervo, la oveja y el lobo"); confiadas e ingenuas ("Los 
lobos y las ovejas").

El León: Abusa de su poder y fuerza, injusto; deja el trabajo pesado para los débiles quedándose con los beneficios ("El león, la vaca, la cabra y la oveja", 15); arrogante pero perdona a los ignorantes (El león y el asno", 17); reflexiona en su vejez por los abusos cometidos contra otros animales ("El león, el jabalí, el toro y el asno", 22); no menosprecia ni daña a los débiles ("El león y el ratón"); justo, agradecido ("El león y el pastor"); mentiroso ("El caballo y el león").

El burro: Imprudente e ignorante (“El león y el asno", 17); imita otro animal para conseguir la estima del amo pero le va mal y recibe palos (El asno y la perrilla", 23); sabio y prudente ("El caballo y el asno").

El cuervo:Ladrón, vanidoso ("El cuervo y la raposa”, 18); listo ("El águila, el caracol y la corneja”, 21).

El zorro, la zorra: Ladrón, adulador (“El cuervo y la raposa”, 18); dañino ("El águila y la raposa", 20); Burlista ("La zorra y la cigüeña"); ladrón ("El lobo, la zorra y el mono"); astuta, envidiosa, imprudente ("La zorra y el lobo"); astuto pero cobarde ("La zorra, el gallo y los perros"); egoísta ("La mona y la zorra").

El águila: Ladrón, prepotente, despreciativa (El águila y la raposa”, 20).

El halcón (milano): Ofensivo con las divinidades ("El milano y su madre", 24).

La rana: Inconforme y arrepentida ("Júpiter y las ranas"); ignorante ("Las liebres y las ranas"); envidiosa, torpe ("La rana y el buey").

El cerdo: Desconfiado (“La puerca y el lobo”). 
La cabra: Prudente frente al lobo, obediente de los padres ("La cabra, el cabrito y el lobo").

La mosca: Molesta a los hombres, se burla de ellos ("El calvo y la mosca"); imprudente ("La mosca y la mula"); ligera e imprudente ("La mosca y la hormiga").

El caballo:Listo y no cae en los engaños (“El caballo y el león”); arrogante, soberbio.

El mono: Sabio y justo (“El lobo, la zorra y el mono"); pide -una mona- favores a quien tiene más que ella ("La mona y la zorra").

Al enumerar las características pertinentes observadas en la lectura o que aparecen con mayor frecuencia entre los personajes de Esopo, destacan entre ellos cualidades como la prudencia en cinco fábulas, la sabiduría y la desconfianza en tres. En cambio, defectos como la prepotencia, la imprudencia y el robo se identifican en tres fábulas cada uno.

Otras virtudes y defectos que aparecen con frecuencia en dos fábulas son: ignorancia, inteligencia, maldad, mentira, hipocresía, egoísmo, codicia, fuerza, justicia, envidia y reflexión. Otras son pertinentes en una tan sola fábula; y estas son: desesperanza, lascivia, cinismo, injusticia, desagradecimiento, libertad, lealtad, conformismo, humildad, astucia, incredulidad, ingenuidad, abuso, arrogancia, agradecimiento, vanidad, adulación, ironía cobardía, inconformidad, obediencia, perversidad, crueldad, confianza, inocencia, oportunismo, imitación y soberbia.

\section{Caracterización de personajes en La oveja negra y demás fábulas de Augusto Monterroso}

La oveja negra y demás fábulas

Es una obra compuesta de cuarenta historias. La oración inicial del relato El conejo y el león ubica al lector en la selva, en un tiempo impreciso y junto a la presencia de un famoso psicólogo 
"semiperdido". Es en este espacio donde se sitúan en adelante los personajes o actantes de las fábulas, y es allí donde se desarrollan las acciones y acontecimientos. Pero el espacio no siempre es nuevo; basta con recordar que en las fábulas esópicas se ubica al lector de golpe en un lugar que puede ser un bosque, una selva, un valle, un río, el campo o la ciudad. A continuación se analizan algunos personajes de las fábulas de Monterroso y se simultáneamente se contrastan sus características pertinentes en relación con los personajes de Esopo.

En el primer relato el psicólogo sube a un árbol y desde este lugar se guarece de los peligros de la selva. Este sitio le sirve para estudiar el comportamiento de los animales y observar el devenir de los hechos. La ubicación espacial del psicólogo precisa la función de este personaje de quien sólo se habla al inicio del libro y no vuelve a aparecer citado en los demás relatos. Su función es iniciar la lectura, y analizar o comparar la conducta de los animales con los hombres.

Este "servicio" del psicólogo es operacionalmente similar al establecido por el narrador en los apólogos de Esopo, en el sentido de precisar los roles de los personajes. Monterroso atrapa al lector hacia sus fábulas asignando al narrador un nuevo papel como observador y estudioso del comportamiento animal-humano. El hecho que sea un psicólogo y no un fabulista (moralista) quien observa el comportamiento de la fauna de la selva para, establecer luego la función comparativa con los animales-hombres y con la selvasociedad, es un elemento que el autor suma al género a partir de la tradición establecida. Como se sabe, el papel del psicólogo en sociedades subdesarrolladas como las nuestras es todavía muy reciente, pero es también la adaptación que conlleva la modernidad y la actualización del papel que antiguamente se asignó a los hombres sabios dedicados a la observación y corrección de la conducta de los miembros de la comunidad, quienes cumplían, de este modo, el papel de guías espirituales y/o morales. El fabulista-moralista es sustituido, en la modernidad, por el psicólogo que opera al mismo nivel, al estudiar y analizar el comportamiento social de los hombres y al establecerse entre ellos la semejanza hombres-animales.

En la primera fábula titulada El conejo y el león de La oveja negra 
y demás fábulas, el acercamiento entre el león y el conejo es claramente una inversión de la conducta tradicional de ambos personajes, y, por supuesto, del género: los dos se encuentran en la selva; el león ruge frente al conejo y éste, reacciona con evidente cobardía y se aleja de la presencia del "rey de la selva". Inicialmente los animales de esta fábula reaccionan de acuerdo a sus conductas tradicionales como en las fábulas esópicas. El narrador es externo, ello proporciona cierto grado de veracidad a lo narrado; pero este narrador observa y describe los sucesos de manera crítica. A partir de lo que parece una conducta "clásica" o "tradicional" en el león (la fuerza y el poder) y en el conejo (la cobardía y la debilidad), Monterroso invierte la conducta y el sentido, puesto que el león es:

"el animal más valiente y maduro, el león ruge y hace gestos y amenaza el universo movido por el miedo; el conejo advierte esto, conoce su propia fuerza y se retira antes de perder la paciencia y acabar con aquel ser extravagante y fuera de sí, al comprender y que después de todo no le ha hecho nada" (Ibid: 12).

Si en las fábulas tradicionales los actantes representan valores y situaciones que se producen en la sociedad; en esta fábula como en otras, la fauna parodia una sociedad mucho más compleja (la sociedad de la modernidad o contemporaneidad) lo cual evidencia, por parte del autor, una conversión exhaustiva de la conducta y de los roles de los animales -léase, de los seres humanos-, cuyo propósito es desenmascarar la realidad actual

Es innegable con ello que la versión y función asignada a las fabulas por Monterroso apunta desde su inicio hacia una reelaboración del género a través de una lectura irónica en la que desaparece la moraleja tradicional ya que ésta, es insuficiente para mostrar la compleja conducta humana de hoy. Se produce entonces una enriquecida versión o lectura, y se ofrece al lector un nuevo y actualizado marco de interpretaciones sobre la conducta humana. En definitiva, con Monterroso estamos frente a una desviación del género realizado asimismo, por conocidos fabulistas como Luis Goytisolo en Fábulas y Bestiario y Confabulario de Juan José Arreola.

Esta “desviación” es posible gracias a la ironía, pero también por 
las nuevas funciones asignadas a los personajes y a la eliminación o desplazamiento del rol tradicional concedido a los personajes de las fábulas de autores como Esopo. Si revisamos la función que cumple la ironía en las "fábulas" de Monterroso, caeremos en la cuenta que es una intencionada tautología del autor frente al género. Pero ello produce un enriquecimiento en el plano semántico debido al tratamiento de los personajes. Marchese dice al respecto de la ironía que ésta, es una forma:

“...de decir algo de tal manera que se entienda o se continúe de forma distinta a la que las palabras parecen indicar: el lector, por tanto, debe efectuar una manipulación semántica que le permita descifrar correctamente el mensaje, ayudado bien por el contexto, bien por una peculiar entonación del discurso." (Ibid: 221).

Horl en su ensayo Ironía y timidez en Monterroso precisa sobre la obra del autor que:

"A la destrucción interior hay que añadir la destrucción del discurso en el plano formal. Ya que es obvio que el conjunto de textos contienen un discurso, una reflexión programática y estética poéticas ex negatione. Pero no es un discurso "normal", presentado en la cómoda forma cronológica (...). Al contrario reina un desorden pérfido, hasta malicioso." (Corral: 55-62).

Aunque la referencia de Horl se basa en el texto Movimiento Perpetuo, la misma, resulta válida -como modelo y función poética desarrollada nuevamente por el autor- en un texto como La oveja negra y demás fábulas. Pero adentrémonos en el desarrollo de los personajes de Monterroso:

\section{El mono:}

Quería ser escritor satírico; estudió mucho, fue a los cócteles a conocer el comportamiento de los animales, fue bien recibido por su conducta encantadora y fue aceptado por los habitantes de la Selva. Llegó a ser el más grande conocedor de la naturaleza animal. Una vez que es socialmente aceptado, aseguró que escribiría contra los ladrones, oportunistas, laboriosos compulsivos, los promiscuos sexuales y contra todos los defectos del género animal. Pero, como 
todos los animales viciosos eran sus amigos y no quería quedar mal con ninguno, renunció a ser escritor crítico y se dedicó a la mística y el amor, por lo que fue considerado loco y desde entonces fue rechazado.

En las fábulas de Esopo el mono conserva su condición de sabio y justo. Sin embargo, Monterroso realiza una severa desviación del mono esópico en cuanto que el de nuestro autor cae víctima de su propio juego social puesto que teme perder la amistad y la admiración de los demás animales. Se inhibe de criticar los defectos y vicios del género animal; asume el misticismo que no es más que el pensamiento dogmático y finalmente es tomado por demente y rechazado por quienes lo "estimaban".

Si las fábulas en Esopo son parodias que muestran los vicios del género humano; en Monterroso las fábulas proporcionan otro nivel de lectura y resultaría un equívoco afirmar que la intención de ellas es estrictamente moralizante. El universo de Esopo es el de la sociedad antigua, la Grecia clásica fuertemente dirigida por el Estado, pero ello no era óbice para el señalamiento de los defectos humanos como los mostrados en las fábulas. Las leyes que presenta el universo fabulario de Esopo resultan; sino elementales, maniqueas y brutales: se es malo o bueno, las fábulas sirven para mostrar la crueldad o la escasa bondad, la infamia, la imposición de la voluntad por la fuerza, el abuso de la fuerza contra los débiles, la imposición de la mentira, los testigos falsos, el egoísmo y la desconfianza, el aprecio por la libertad, los acuerdos ventajosos en contra de otros, la injusticia, la codicia, la lealtad y la deslealtad, el desprecio hacia los viejos, el conformismo, el humilde sacrificado por los fuertes, el ladrón, la disposición al sacrificio, el libidinoso, el listo y prudente o el sabio y a veces reflexivo, el malo y perverso, la sinrazón de la verdad, el falso, el desconfiado, el aprecio a la verdad sobre los bienes materiales, el codicioso, el ingenuo, el arrogante, el justo con los débiles, el agradecido, el vanidoso, el adulador, el prepotente, el inconforme, el ignorante, el obediente de los padres, etc. Pero este universo resulta demasiado hermético y su lectura no deja de ser lineal para una época como la nuestra.

En la fábula El sabio que tomó el poder, el mono deduce que su 
descendencia -el hombre- es inteligente. Lee libros; sus consejeros la zorra, el búho y la serpiente lo ayudan para que progrese. El mono asciende hasta convertirse en secretario del león. Descubre más tarde que él posee más inteligencia que el león y convence, a éste último, para cambiar los papeles. El león accede pero cada vez que el mono da una orden o regaña al león, el mono recibe un zarpazo en el cuerpo. Tiempo después el mono ruega al león para que las cosas vuelvan a ser como antes: el león amo de la selva y el mono su secretario. Es esta una amarga fábula de la modernidad y sobre la condición inamovible del poder y de los poderosos; y, por supuesto, es la afirmación de una sociedad en la que no hay transformaciones y donde valores como la inteligencia, la sabiduría o el conocimiento están definitivamente relegados frente a la brutalidad de la fuerza.

En La mosca que soñaba que era un águila los sueños de grandeza de seres insignificantes contrasta con su realidad. En esta fábula la mosca acostumbrada a la inmundicia descubre que la forma del águila no le sirve para sus hábitos y propósitos. Sin embargo el insecto no ceja de soñar con la grandeza del águila y sólo por las noches descansa de esta inquietud. Los latinos tenían el aforismo: "Aquila non capit muscas" (el águila no caza moscas) sintetizando en esta frase -de tono imperialista-, que para los grandes no cuentan las insignificancias. La mosca de Esopo difiere de la de Monterroso en tanto que molesta e incomoda a los hombres, se burla de ellos y es ligera e imprudente. La mosca de Monterroso encierra una historia compleja, pero aparentemente banal: es el mediocre, el ser insignificante que sueña con la grandeza que otros poseen.

“La fe mueve montañas" es el refrán cuya idea antípoda se encuentra en la fábula La fe y las montañas. La fe como sujeto mueve montañas sólo y cuando ello sea necesario; pero una vez extendida la fe, la gente mueve indistintamente las montañas. Entonces para no ocasionar problemas y ubicar con certeza las moles de tierra, la gente dejó la fe y las montañas ya no se movieron de su lugar. Monterroso por medio de la ironía invierte la fábula de este refrán e invierte la conducta de los sujetos y objetos que lo componen. El resultado es un cambio en el sentido original del aforismo, produciendo un enriquecimiento y una nueva lectura del plano 
semántico y con ello, desmorona frases que no resisten una duda.

En “La tela de Penélope o quién engaña a quién” la fábula presenta una inversión y reinterpretación de la conducta de los personajes de La Odisea y ello produce una relectura e irónica semantización. En la fábula de Monterroso Ulises además de sabio es astuto

-Como si ambos aspectos fuesen contradictorios-, y Penélope además de bella es tejedora; "defecto" que le permite el beneficio de la soledad para tejer largas temporadas. Pero la conducta de ambos se explica de forma tal que desaparece el mito que da curso a la leyenda. Ulises en verdad, huye de su hogar cada vez que Penélope se hunde en sus largas temporadas de tejedora; pero también Ulises se busca a sí mismo en sus largos viajes en tanto que Penélope engaña a sus pretendientes con el cuento que Ulises anda de viaje. En realidad nada es cierto puesto que Homero además de ciego dormía a menudo y por lo tanto, no podía enterarse de toda la verdad del mito. Homero es integrado como personaje y forma parte de la fábula. Lo que Monterroso hace en este relato, es fundamentar la "verdadera" fábula y "corregir" la historia equivocada que todos los lectores conocemos. Podemos hablar aquí de una meta fábula: la inversión de la conducta de los personajes mitológicos obliga a una relectura y/o reinterpretación de un "clásico"; estableciendo con ello, que nada es lo que parece ser; ni siquiera las referencias literarias mitológicas que poseemos de personajes de la literatura universal.

La oveja negra conserva la característica fundamental de los corderos de Esopo; sigue siendo ingenua y víctima de otros animales de la selva-sociedad. Pero Monterroso desplaza e historiza su condición de martir ya que son muchas más las víctimas -después de la primera oveja negra- las ovejas, de igual color, que son fusiladas o sacrificadas. Posteriormente, el rebaño (de ovejas blancas) arrepentido, le erige una estatua a cada oveja negra sacrificada. La oveja negra parodia a las eternas víctimas de la humanidad; desde los mártires de las religiones, los héroes fundacionales de la historia de nuestros países, los caídos por la segregación ideológica y racial, los apocalípticos de la modernidad, las lesbianas y homosexuales excluidos y los rebeldes y suicidas "dark" de la pos- 
modernidad cuyas acciones -inaceptables para el status quo- los lleva al sacrificio o la auto-inmolación. En todo caso -los ejemplos sobran-, la sociedad los reduce o anula a la simple condición de héroes.

Si la función del espejo es reflejar, en la fábula El espejo que no podía dormir resulta ser un cristal neurótico que pretende proyectar además de una imagen la conciencia de la realidad. Se siente inexistente porque nadie lo usa, es ignorado y por tanto, poco útil. Sin embargo se muestra diferente a los otros espejos (¿Hamlet de Shakespeare?). En Monterroso los objetos no cumplen una función establecida por la costumbre o la tradición; los sujetos y objetos son revalorados; y por ello, muestran un proceso de cavilación y autorreflexión por parte del autor: es un juego, pero las cosas u objetos adquieren valoraciones y preocupaciones ontológicas.

En El búho que quería salvar a la humanidad encontramos al propio escritor que se ríe de su papel fabulador y de sus pretensiones de sabiondez y escudriñador de los hábitos y defectos de la gente; es otra meta-fábula en la que el búho concluye que los males de los animales se enderezan si todos (animales y humanos) actúan de forma apropiada y diferente.

Son otros los animales que integran las fábulas de Augusto Monterroso como El camaleón que finalmente no sabía de qué color ponerse. Acertadamente y por su evidente connotación, Monterroso relaciona este animal con la actividad del político. Función dotada de esa diversidad de máscaras que asumen los intermediarios y negociantes de la política y que les asigna esa conducta camaleonesca. Empero, en esta fábula el reptil entra en choque con el resto de animales que son asesorados -convenientemente- por la zorra; quien además, da la solución para desenmascarar y evitar la ambigüedad e hipocresía del camaleón. Pero esta dilogía extendida encubre los convencionalismos universalmente aceptados y expresados a través de la hipocresía y civilidad. Monterroso desentraña ese mecanismo de ambivalencias simples y socialmente estructuradas. Esta fábula al igual que La oveja negra revela los artificios sociales acatados y pocas veces cuestionados. 
Otros personajes de Monterroso son una propuesta de metafabulación a partir de personajes de fábulas, libros e historias conocidas. Por ejemplo: La cucaracha soñadora (Franz Kafka), (49), Pigmalión (Bernard Shaw), (55-57), Sansón y los Filisteos (La Biblia), (65), El burro y la flauta (La Fontaine), (75). En todos ellos se opera una inversión en la conducta tradicional de los actantes y por supuesto, son un ejemplo de intertextualidad que el autor desarrolla.

Las características pertinentes en los personajes de Monterroso señalan que la Reflexión aparece en ocho de sus fábulas, la Sabiduría aparece en siete y la Inteligencia en tres. Hay otras características cuya presencia y frecuencia es de dos fábulas y ellas son: crueldad e incomprensión. Otras pertinencias que poseen una frecuencia son: ignorancia, lascivia, prudencia, injusticia, hipocresía, fuerza, ingenuidad, prepotencia, abuso, justicia, imprudencia, valentía, inconformidad, engreimiento, inseguridad, vergüenza y perseverancia.

\section{Conclusión}

Al analizar y comparar las características pertinentes entre los personajes del libro Fábulas de Esopo y La oveja negra y demás fábulas de Augusto Monterroso se aprecia que las fábulas de Monterroso operan en mayor grado con conductas y cualidades como: la Reflexión (8), Sabiduría (7) e Inteligencia (3). Estas características señalan una función racionalizante en el papel asignado a los personajes. Lo señalado aquí es la acción, actividad o proceso efectuado por los personajes de Monterroso.

Sin embargo ello no es suficiente para explicar la desviación o desplazamiento de los personajes de Monterroso en relación a los personajes de Esopo. Existen otros elementos a tomar en cuenta que operan y dan un mayor sentido a este desplazamiento en la estética de Monterroso y ello es la ironía; que no es más que la actitud crítica del autor hacia el género y los personajes, lo cual asigna una función distanciadora, reflexiva e iconoclasta con respecto a los modelos impuestos por la tradición esópica. A menudo, y al hacer este trabajo, se percibe la función distanciadora que el dramaturgo alemán Bertolt Brecht asignó a su teatro. Brecht exigía 
una actitud analítica, intelectual y crítica al asumir un personaje. Su técnica denominada "distanciación" o "extrañamiento", no ha sido más que un "Procedimiento para distanciar la representación de manera que el objeto representado aparezca bajo una nueva perspectiva que revele un aspecto oscuro o demasiado familiar" (Pavis: 147-149). Ello quiere decir, en términos escénicos, que en esta técnica el actor (o actante) no encarna a su personaje sino que lo muestra y mantiene una distancia crítica con respecto a él. Actitud similar presenta Monterroso al de construir el universo fabulario de la tradición literaria y al reestructurar y sostener, a través de la ironía, otro universo paralelo, pero enriquecido y actualizado.

Es innegable que aspectos como el tono y la atmósfera asignan a las fábulas de Monterroso una función crítica opuesta a la dominante función moralizadora de los personajes de Esopo y de toda la tradición fabularia. Monterroso trasciende el maniqueísmo y asigna condiciones existenciales, psicológicas y ontológicas que no poseen los actantes arquetípicos de las fábulas de Esopo. Los personajes en Monterroso se muestran oblicuos, actuales y menos simbólicos o arquetípicos; aunque eso sí, profundamente humanos, no estereotipados y por ello impredecibles al evitar los lugares comunes. Poseen hondura y complejidad, son conscientes y contradictorios; reflexionan, deducen e infieren. Finalmente en sus personajes predomina la sorpresa, lo ambivalente y el absurdo.

Los personajes de las fábulas de Esopo con sus características pertinentes resultan insuficientes para explicar, en la actualidad, una dinámica psico-socio-cultural de los actantes en una modernidad, o más aún, en la compleja posmodernidad de nuestros días. En Esopo las características pertinentes señalan a: la Prudencia (5), la Sabiduría (3), la Desconfianza (3), la Prepotencia (3), la Imprudencia (3) y el Robo (3) como las más constantes. Pero estas características no explican ni resultan suficientes para exponer un proceso de introyección y reflexión profunda sobre la compleja conducta humana de hoy.

Como ya se dijo las fábulas en Esopo apuntan hacia lo moral, el aprendizaje de lo bueno con respecto de lo malo. Es un mundo de 
relaciones rígidas y predecibles. Los pensamientos de los personajes en Esopo resultan básicos; padecen las acciones de otros y el tono predominante en ellos es el pesimismo, la crueldad y su finalidad es siempre pedagógica. Al analizar los personajes particularmente en el caso de Monterroso, no se debe obviar el papel desempeñado por los elementos estructurales de cada fábula que se suman para que se produzca el desplazamiento señalado. Me refiero a las situaciones y conflictos que en su conjunto enriquecen el nuevo papel que nuestro autor asigna a los personajes herederos de una tradición. 


\section{Bibliografía}

- ALBA, Editorial. (1998) La Fábula: expresión y manifestación humanas, en Fábulas Literarias estudio introductorio sobre Tomás de Iriarte, España.

- Bal, Mieke, (1990) Teoría de la narrativa (Una introducción a la narratología), 3era. Edición, Madrid, Ediciones Cátedra.

- Barraza, Marco Antonio. (1999). Antología de escritores del Istmo Centroamericano. Edit. Clásicos ROSXIL, Primera edición. El Salvador.

- Corral, Hill H. (1995), Refracción. Augusto Monterroso ante la crítica. Ediciones Era, Primera edición.

- De Iriarte, Tomas. (1998). Fábulas Literarias. Editorial ALBA, España.

- Esopo. (1999). Fábulas esópicas. Editorial Melsa, S.A., España.

- Marchese, Angelo y Forradelas Joaquín. Diccionario de retórica, crítica y terminología literaria, $1^{\text {a }}$. Edición, España, 1986, Pág. 161.

- Monterroso, Augusto. (1981). La oveja negra y demás fábulas. Edtorial Seix Barral, España.

- Pavis, Patrice. (1983), Diccionario del Teatro: Dramaturgia, estética, semiología, Editorial Paidós, España. 